\title{
ELECTROOPTIC AND DIELECTRIC PROPERTIES OF NEW ANTIFERROELECTRIC LIQUID CRYSTAL MIXTURES
}

\author{
G. ANDERSSON ${ }^{\mathrm{a}}$, R. DABROWSKI ${ }^{\mathrm{b}}, \mathrm{W}$. DRZEWINSKI ${ }^{\mathrm{b}}$, \\ J.P.F. LAGERWALL ${ }^{\mathrm{a}}$, M. MATUSZCZYK ${ }^{\mathrm{a}}$, T. MATUSZCZYK ${ }^{\mathrm{a}}$, \\ P. PERKOWSKI ${ }^{\mathrm{b}}, \mathrm{Z}^{\mathrm{Z}}$ RASZEWSKI ${ }^{\mathrm{b}}$ \\ ${ }^{a}$ Chalmers University of Technology, S-412 96 Göteborg, Sweden; \\ ${ }^{b}$ Military University of Technology, PL-00-908 Warszawa, Poland
}

Two new antiferroelectric liquid crystal mixtures based on optically active hydroxyesters have been studied with respect to their electro-optic and dielectric behavior. The mixtures exhibit only a SmA* phase above $\mathrm{SmC}_{\mathrm{a}}{ }^{*}$ and show a stable antiferroelectric order over a broad temperature range $\left(\approx 100^{\circ} \mathrm{C}\right)$. Electro-optic as well as dielectric studies suggest that the $\mathrm{SmC}_{\mathrm{a}}{ }^{*}-\mathrm{SmA}$ * transition is second order. In thin cells signs of a surface-induced $\mathrm{SmC}^{*}$ phase has also been observed. We present the relevant characteristics for three different electro-optic modes which could be exploited in these materials, including the very fast linear mode for sub-threshold voltages.

$\underline{\text { Keywords }}$ ferro- and antiferroelectric liquid crystals; electro-optic switching; dielectric spectroscopy; surface-induced phases

\section{INTRODUCTION}

Molecular engineering of antiferroelectric liquid crystals is not a straight-forward task, and considerable efforts still have to be devoted to increase the stable range of the $\mathrm{SmC}_{\mathrm{a}}$ * phase. In this article we describe electro-optic and dielectric studies on two eutectic mixtures of four 
individual compounds (Figure 1). The synthetic strategy and procedure have been described in [1] and the physical properties of the pure components in [2]. The pure components (1) and (2) both show $\mathrm{SmI}_{\mathrm{a}}{ }^{*}$ phases, but in the mixtures these have been successfully suppressed.

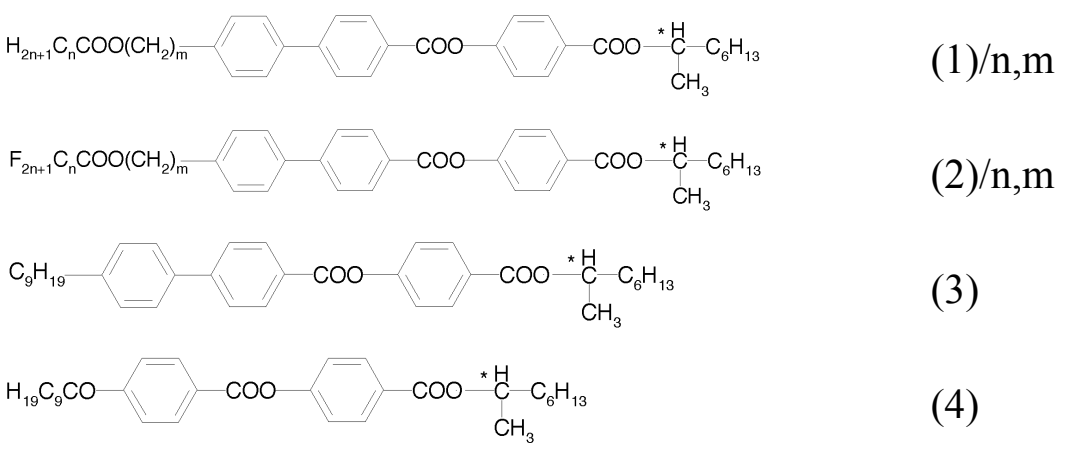

FIGURE 1 Components used for the mixtures W101 and W101A

The composition of the W101 mixture, by weight, is:

$28.80 \%$ of (1) with $n=3$ and $m=3 ; 13.97 \%$ of (1) with $n=5$ and $m=3$;

$35.19 \%$ of (1) with $n=6$ and $m=3 ; 9.05 \%$ of (3); $13.0 \%$ of (4).

The other mixture under study, W101A, was obtained by adding $10 \%$ (by weight) of the fluorinated compound (2) with $n=m=3$, to W101. The phase sequences, as obtained with DSC on heating, are:

$$
\begin{array}{ll}
\text { W101: } & \mathrm{X} \bullet 6.6 \bullet \mathrm{SmC}_{\mathrm{a}} * \cdot 70.5 \cdot \mathrm{SmA}^{*} \bullet 97.6 \bullet \text { Iso } \\
\text { W101A: } & \mathrm{X} \bullet<-20 \cdot \mathrm{SmC}_{\mathrm{a}} * \bullet 80.5 \cdot \mathrm{SmA}^{*} \cdot 101.5 \bullet \text { Iso }
\end{array}
$$

Thus, adding the fluorinated compound broadens the stable temperature range of the antiferroelectric phase, which makes the mixture W101A more suitable for applications. However, the $\mathrm{SmC}_{\mathrm{a}}{ }^{*}$ phase of W101 can be supercooled down to $-20^{\circ} \mathrm{C}$.

The mixtures based on the fluorinated compounds generally exhibit larger tilt angles and higher values of the spontaneous polarization. A 45 degree tilt material based on compound (2) is described in [3].

\section{EXPERIMENTAL}

For the electro-optic characterization we have used shear cells and commercially available E.H.C. cells with a cell gap of $2 \mu \mathrm{m}$ and $19 \mu \mathrm{m}$, respectively. The thin cells have been prepared in our clean room facilities 


\section{G. ANDERSSON et al.}

using glass substrates coated with low resistivity ITO electrodes and $1000 \AA$ A thick aligning/protection layers of $\mathrm{SiO}_{\mathrm{x}}$, evaporated at normal incidence. The cells are filled under vacuum and finally the liquid crystal is oriented by gentle shearing of the plates and application of an AC field over the sample. The E.H.C. cells have buffed polyimide alignment layers. Electric fields were applied to the samples using a Leader LFG1300 function generator in combination with an FLC Electronics F20ADI high voltage linear amplifier. Electro-optic investigations were followed optically by using a Zeiss polarizing microscope equipped with a Mettler FP52 hot stage for temperature control within $0.1{ }^{\circ} \mathrm{C}$, and monitored by a digital storage oscilloscope Tektronix TDS540.

The $\mathrm{P}_{\mathrm{s}}$ measurements monitor the total induced polarization when the sample is switched to a completely saturated ferroelectric state. The measurements have been done using the AC-bridge technique and further confirmed by a straight-forward current peak integration [4]. The tilt angle has been measured between the opposite field-saturated positions of the director by means of the turn table of the polarization microscope.

Dielectric spectroscopy measurements were performed in the range $10 \mathrm{~Hz}$ to $13 \mathrm{MHz}$ using the HP4192A dielectric bridge. We have used self-made planar-oriented cells of varying thickness $(2-36 \mu \mathrm{m})$ with polyimide or $\mathrm{SiO}_{\mathrm{x}}$ alignment layers. As temperature controller we have used the Mettler FP82 and the liquid crystal alignment was observed through a Leitz polarizing microscope.

\section{RESULTS AND DISCUSSION}

\section{Electro-optic Measurements}

The spontaneous polarization and tilt angle, as function of temperature, are very similar in the two mixtures, as can be seen in Figure 2 . At $50^{\circ} \mathrm{C}$, where the tilt is well saturated ( $\sim 25$ degrees), the response time $\tau$ lies around $10 \mu \mathrm{s}$. As the $\mathrm{P}_{\mathrm{s}}$ value only rises slowly, most of its temperature dependence is due to the viscosity $\left(\tau \sim \gamma / \mathrm{P}_{\mathrm{S}} \mathrm{E}\right)$.

The threshold field for the transition to the ferroelectric state has been measured in samples with different thickness, and was in general found to be independent of the cell gap, thus a material property (Figure 3 ). For electric field strengths below threshold (Figure 4) we observe that the response time does not depend on the applied voltage. In this region the response is linear with the field (undistorted), a property which it shares with the ferroelectric soft mode (electroclinic effect) [5]. 
ELECTROOPTIC AND DIELECTRIC PROPERTIES...

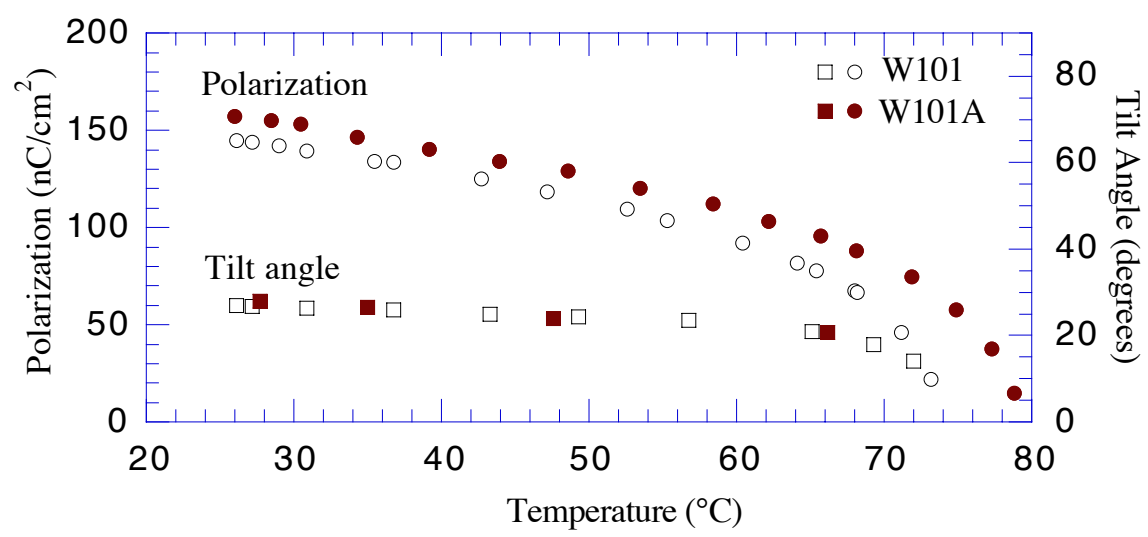

FIGURE 2 Spontaneous polarization $\mathrm{P}_{\mathrm{S}}$ and tilt angle $\theta$ as a function of temperature. The measurements were made in thin cells. Due to the electroclinic effect non-zero values for polarization and tilt (in this case fieldinduced quantities $\mathrm{P}_{\mathrm{i}}$ and $\theta_{\mathrm{i}}$ ) are measured above the $\mathrm{SmC}_{\mathrm{a}}{ }^{*}-\mathrm{SmA}^{*}$ transition.

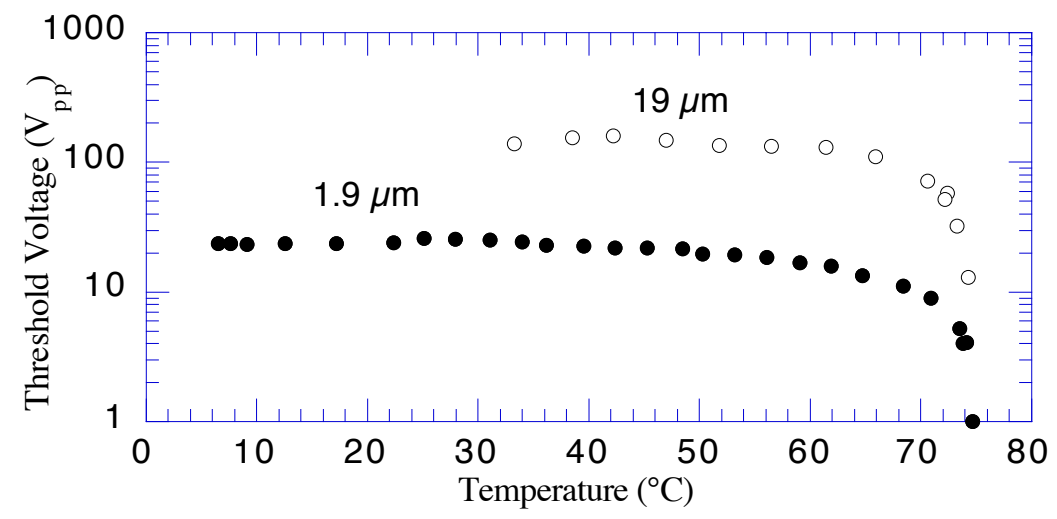

FIGURE 3 Threshold voltage $\mathrm{V}_{\mathrm{pp}}$ at quasi dc-conditions for the field-induced transition to the ferroelectric state in $\mathrm{W} 101 \mathrm{~A}$, measured in $1.9 \mu \mathrm{m}$ and $19 \mu \mathrm{m}$ samples. The critical field $\mathrm{V}_{\mathrm{pp}} / \mathrm{d}$ is independent of the thickness, within the measurement accurancy, and also independent of temperature for saturated tilt.

An interesting property of the linear (high frequency [6][7]) optical response is illustrated in Figure 5. The upper curve (f) shows the response to a sinusoidal driving field of constant level well below the threshold voltage (cf. Figure 3). Contrary to the soft mode, the amplitude of the high frequency response is nearly constant in temperature within the antiferroelectric phase. The divergence typical for a second order transition to the $\mathrm{SmA}^{*}$ phase is indicated around $75^{\circ} \mathrm{C}$. Above this temperature the characteristic decay of the soft mode is observed. The second curve is the amplitude of the low frequency response in the antiferroelectric phase. The mechanism behind this response is still controversial but can be in- 


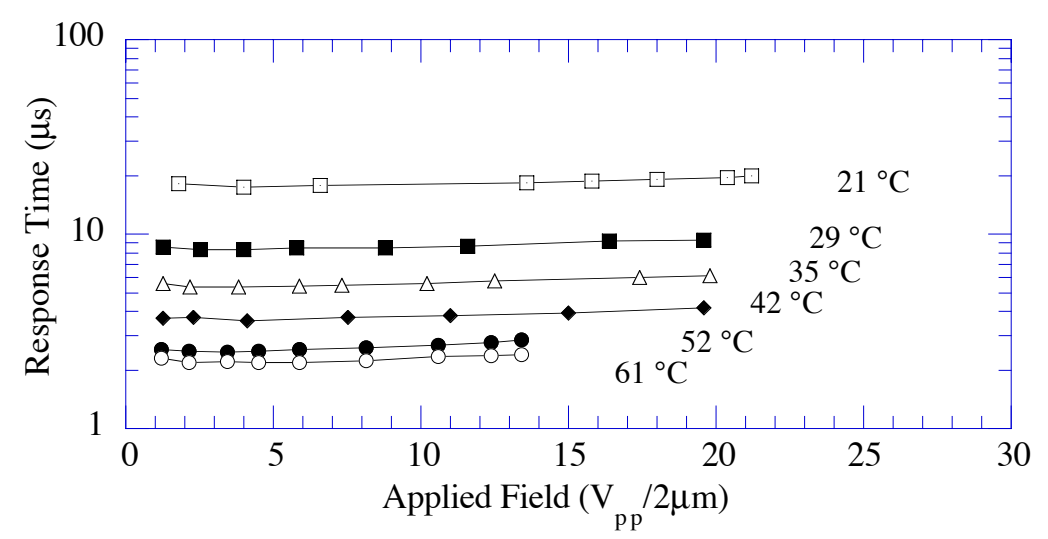

FIGURE 4 Response time of W101A at different temperatures in the linear regime, i.e. below the AF-F threshold. The response is field-independent.

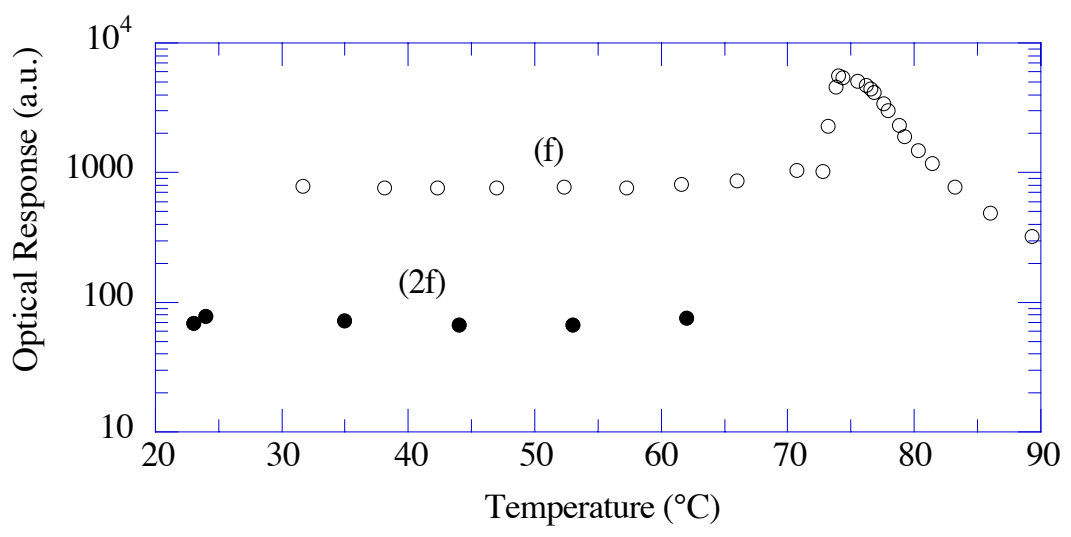

FIGURE 5 The amplitude of the "small signal" optical response in W101A to a sinusoidal driving field as a function of temperature.

terpreted as a modulation of the effective birefringence of the liquid crystal, since it is most clearly seen in samples with random planar alignment, where the linear response is suppressed by spatial averaging [8].

The linear response upon applying small electric fields has been further studied by cut-off frequency measurements (Figure 6). This parameter has been defined according to the electronic definition, i.e. as the frequency at which the response amplitude has decreased by factor $1 / \sqrt{ } 2$. The lower curve (2f) corresponds to an optical response at twice the applied electric field frequency (quadratic effect). At temperatures above $70^{\circ} \mathrm{C}$ only one response mode, the soft mode, is resolved and the charac- 


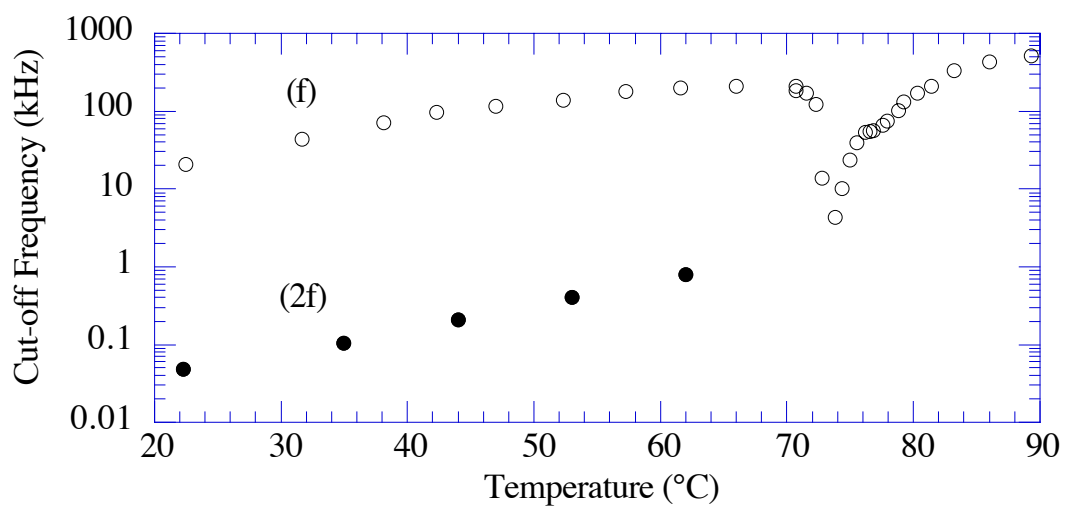

FIGURE 6 The cut-off frequency for three response modes in W101A as a function of temperature. The upper curve (f) indicates the linear response.

teristic soft mode-dip in the relaxation frequency, typical for a second order phase transition is observed.

A very interesting property of the AFLC driven below the threshold voltage is that the induced tilt angle does not depend on the temperature. In Figure 7 we illustrate the induced tilt as a function of applied field at various temperatures. All the values fall on the same curve (within the measurement error) which proves that the effect is temperature independent, contrary to the ferroelectric soft mode (electroclinic) effect, which exhibits a critical behavior with temperature. The linear response amounts to a pure deflection of the optic axis while the change in the average birefringence has been disregarded.

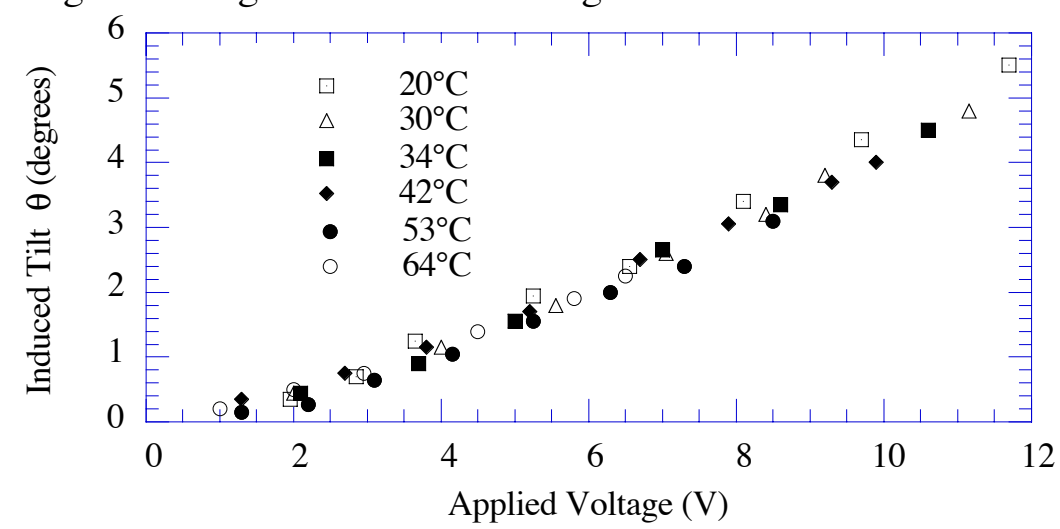

FIGURE 7 Induced tilt $\theta$ in the linear regime of W101A as a function of applied field at $20^{\circ} \mathrm{C}$ to $64^{\circ} \mathrm{C}$. 
Our electro-optic investigations essentially confirmed the previously given phase sequences for both W101 and W101A. However, the phase transition temperatures depend on the cell thickness. Thus the SmA* phase is stabilized in thin cells, existing down to $73^{\circ} \mathrm{C}$ in $\mathrm{W} 101 \mathrm{~A}$ for $\mathrm{d}=2 \mu \mathrm{m}$, cf. below. Furthermore, in thin samples the electro-optic response just below the $\mathrm{SmA}^{*}-\mathrm{SmC}_{\mathrm{a}}$ * transition resembled that of coexisting $\mathrm{SmC}^{*}$ and $\mathrm{SmC}_{\mathrm{a}}{ }^{*}$ phases [9], cf. Figure 8, which could mean that the surfaces induce a synclinic structure in a narrow temperature interval below the transition.

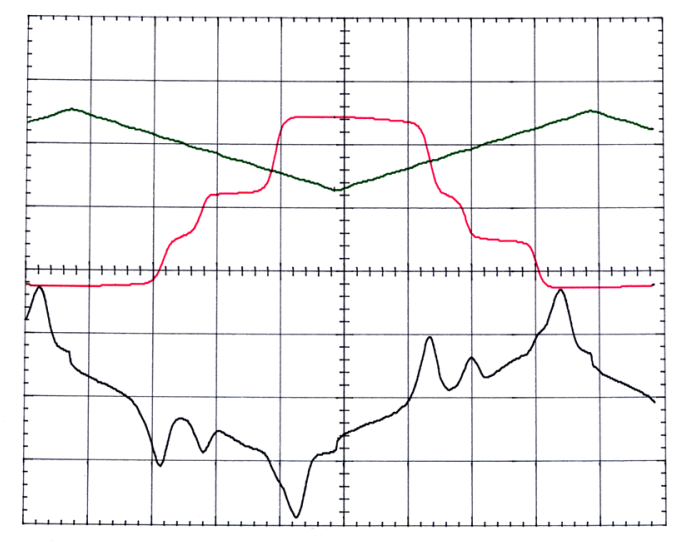

FIGURE 8 The optical response (middle curve) and the current response (lower curve) of W101A in a $2 \mu \mathrm{m}$ cell at $74.3^{\circ} \mathrm{C}$ to a triangular applied voltage (upper curve). The behavior at this temperature may be explained in terms of coexistence of $\mathrm{SmC}^{*}$ and $\mathrm{SmC}_{\mathrm{a}}{ }^{*}$.

\section{Dielectric Spectroscopy Measurements}

The $\mathrm{SmA}^{*}-\mathrm{SmC}_{\mathrm{a}}{ }^{*}$ phase sequence, with no intermediate phases, was confirmed with dielectric spectroscopy measurements on thick cells $(\geq 23 \mu \mathrm{m})$, in which the results on cooling and on heating were furthermore more or less identical. However, measurements on cells of $2 \mu \mathrm{m}$ thickness revealed a different behavior in the vicinity of the phase transition temperature for both compounds. Figure 9 shows the spectra for W101 in a $36 \mu \mathrm{m}$ (left) and in a $2 \mu \mathrm{m}$ (right) cell, on cooling. While the left spectrum features a normal $\mathrm{SmA}^{*}-\mathrm{SmC}_{\mathrm{a}}{ }^{*}$ transition, distinguished by a $\mathrm{SmA}$ * soft mode with an absorption maximum just above the transition and a fairly sharp drop below it, the right spectrum contains an additional medium-frequency absorption which is not typical of either a $\mathrm{SmA}^{*}$ or a $\mathrm{SmC}_{\mathrm{a}}$ * phase, just below the transition temperature. 

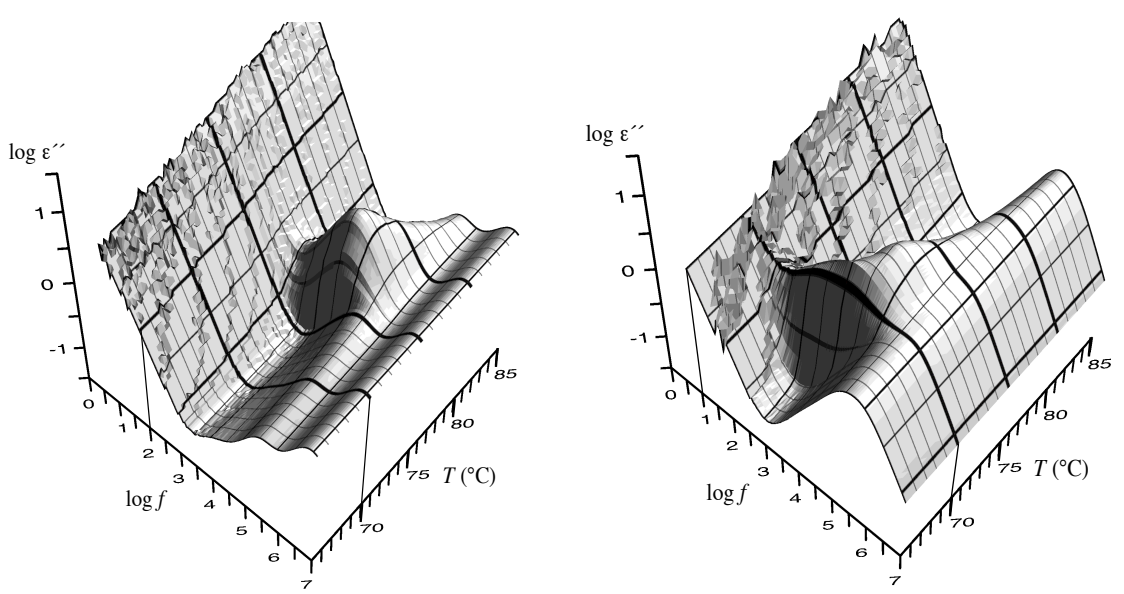

FIGURE 9 Dielectric absorption spectra for W101 in a $36 \mu \mathrm{m}$ (left) and in a $2 \mu \mathrm{m}$ (right) cell, obtained with $1 \mathrm{~V}$ and $0.3 \mathrm{~V}$ measuring voltage, respectively. Both measurements were performed on cooling in planar-aligned samples. The constant absorption around $1 \mathrm{MHz}$ in the right spectrum is due to the cell relaxation, which in thin cells becomes very pronounced and disturbs the actual liquid crystal spectrum.

Furthermore, the $\mathrm{SmA}^{*}$ phase temperature range is extended in the thin cell where the transition occurs approximately $5^{\circ} \mathrm{C}$ lower than in the thick cell. On heating, the additional absorption is absent, but also here the transition temperature is shifted downwards in the thin cell. In W101A the surface-induced additional absorption also appears, but not quite as
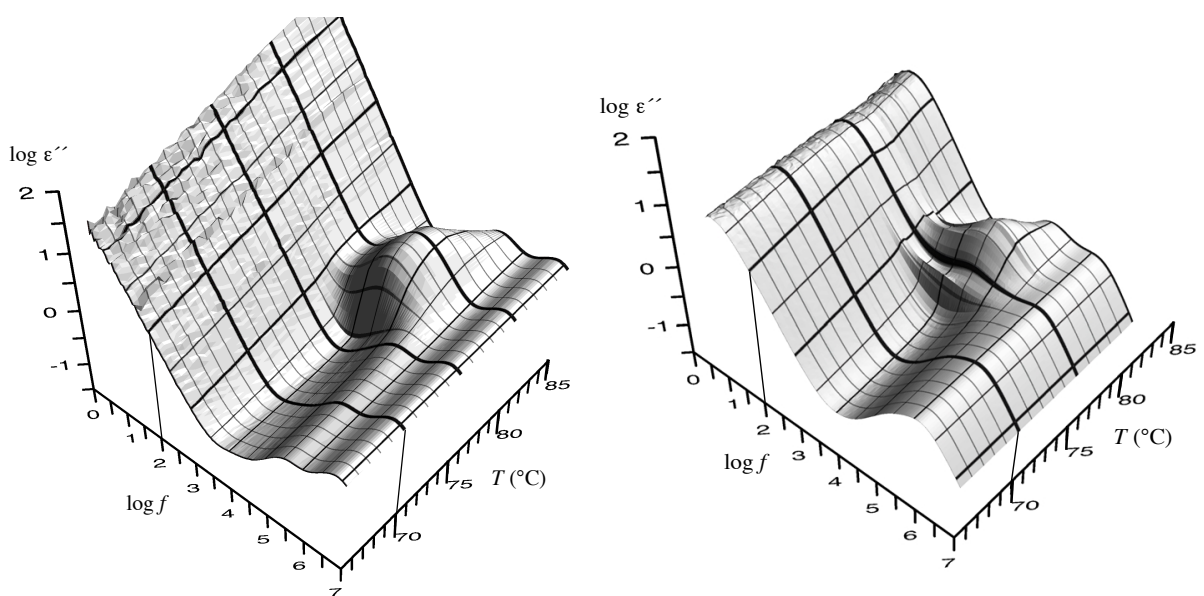

FIGURE 10 Dielectric absorption spectra for W101A in a $23 \mu \mathrm{m}$ (left) and in a $2 \mu \mathrm{m}$ (right) cell. Both measurements were performed with $0.3 \mathrm{~V}$ measuring amplitude, on cooling in planar-aligned samples. The constant absorption around $1 \mathrm{MHz}$ in the right spectrum is due to the cell relaxation. 
pronounced (Figure 10). On the other hand, it is in this compound present also on heating.

The anomalous absorptions observed in the $2 \mu \mathrm{m}$ samples resemble that of the phason mode typical of $\mathrm{SmC}^{*}$ samples, and may thus be interpreted as a sign of a surface-induced $\mathrm{SmC}^{*}$ phase just below the $\mathrm{SmA}^{*}$ phase. Such a coexistence of phases would also explain the electro-optic switching behavior observed in thin W101A samples in the vicinity of the $\mathrm{SmA}^{*}-\mathrm{SmC}_{\mathrm{a}}{ }^{*}$ phase transition temperature (see Figure 8). Several reports now exist where it has been observed that strong surface influence promotes a synclinic, or ferroelectric, ordering of chiral smectic phases (see for instance [10]), which is reasonable since a surface will not easily accept a structure where the polarization direction alternates between out of and into the surface.

\section{CONCLUSIONS}

The mixtures studied both show typical antiferroelectric behavior, as observed both with electro-optic and dielectric measurements. A broad $\mathrm{SmC}_{\mathrm{a}}{ }^{*}$ temperature range makes W101A suitable for applications. It switches between the ferroelectric states with a characteristic time of about $30 \mu$ s at a typical device operating temperature of $35^{\circ} \mathrm{C}$. Including its soft mode in the $\mathrm{SmA}^{*}$ phase and its fast linear mode in $\mathrm{SmC}_{\mathrm{a}}{ }^{*}$, this mixture shows a rich and interesting variety of electro-optic modes. Just below the SmA* phase, thin samples of both compounds behave as if a synclinic $\left(\mathrm{SmC}^{*}\right)$ phase is present together with the anticlinic $\mathrm{SmC}_{\mathrm{a}}{ }^{*}$ phase. This behavior is observed both electro-optically and by means of dielectric spectroscopy.

\section{ACKNOWLEDGEMENTS}

This work has been funded by the Swedish Foundation for Strategic Research and Polish Committee for Scientific Research (KBN).

\section{References}

[1] W. Drzewinski, R. Dabrowski, K. Czuprynski, J. Przedmojski, M. Neubert, Ferroelectrics, 212, 281 (1998) 
[2] A. Fafara, B. Gestblom, S. Wrobel, R. Dabrowski, D. Kilian, W. Haase, Ferroelectrics, 212, 79 (1998)

[3] K. D’havé, A. Dahlgren, J.P.F. Lagerwall, G. Andersson, P. Rudquist, M. Matuszczyk, S.T. Lagerwall, R. Dabrowski, W. Drzewinski, this Conference

[4] G. Andersson, Thesis, Department of Physics, Chalmers University of Technology, Göteborg, Sweden (1992)

[5] S. Garoff, R.B. Meyer, Phys. Rev. Lett., 38, 848 (1977)

[6] K. Skarp, G. Andersson, S.T. Lagerwall, H. Kapitza, H. Poths, R. Zentel, Ferroelectrics, 122, 127 (1991)

[7] G. Heppke, J.M. Hollidt, D. Lötzsch, D. Moro, Freiburger Arbeitstagung, P41 (1996)

[8] M. Buyvidas, F. Gouda, G. Andersson, S.T. Lagerwall, B. Stebler, J. Bömelburg, G. Heppke, B. Gestblom, Liquid Crystals, 23, No.5, 723 (1997)

[9] P. Rudquist, D. Krüerke, J. P. F. Lagerwall, S. T. Lagerwall, N. A. Clark, J. E. Maclennan, D. M. Walba, this conference

[10]P. Rudquist, J.P.F. Lagerwall, M. Buivydas, F. Gouda, S.T. Lagerwall, N.A. Clark, J.E. Maclennan, R. Shao, D.A. Coleman, S. Bardon, T.Bellini, D.R. Link, G. Natale, M.A. Glaser, D.M. Walba, M.D. Wand, W.H. Chen, J. Mater. Chem., 9, 1257 (1999). 